\title{
Alternatives to left lateral sector in paediatric liver transplantation - a systematic review on monosegmental and reduced grafts
}

\author{
Paschalis Gavriilidis ${ }^{1}$, Ernest Hidalgo ${ }^{2}$ \\ ${ }^{1}$ Department of Hepatopanceaticobiliary Surgery. Imperial College Healthcare NHS Trust, Hammersmith Hospital, London, UK; ${ }^{2}$ Department of \\ Hepato-Pancreatic-Biliary Surgery and Liver Transplantation, Hospital Universitari Vall d'Hebron, Barcelona, Spain \\ Contributions: (I) Conception and design: Both authors; (II) Administrative support: None; (III) Provision of study materials or patients: Both authors; \\ (IV) Collection and assembly of data: Both authors; (V) Data analysis and interpretation: Both authors; (VI) Manuscript writing: Both authors; (VII) \\ Final approval of manuscript: Both authors. \\ Correspondence to: Paschalis Gavriilidis, MD, MSc, PhD. Imperial College Healthcare NHS Trust, Hammersmith Hospital, London W12 0HS, UK. \\ Email: pgavrielidis@yahoo.com.
}

Background: Paediatric liver transplantation (pLT) is the treatment of choice for many liver conditions.
However, it still poses relevant challenges, mainly related to the size of the recipients. Unlike in adults, excessive
graft volume might represent an issue when the estimated graft-recipient-weight-ratio (GRWR) is significantly
disproportionate. In this situation, the traditional left lateral sector (LLS) grafts are too big and other alternatives
are required, such as monosegmental or reduced (including hyper-reduced) grafts (RLLS/HRLLS). Results with
conventional LLS-pLT are excellent and replicating them with monosegmental or RLLS is challenging given (I)
the technical complexity and (II) the need to overcome the large-for-size scenario. This article is to review the
existing experience with monosegmental, RLLS/HRLLS grafts and appraise its results. Methods: Systematic search of the electronic databases, conducted from their inception until May 2020.

Results: After scrutiny of the available literature, 16 studies were included reporting 330 patients transplanted with monosegmental and RLLS/HRLLS grafts. There were 10 re-grafts (6 of them $<90$ days); 90\% of grafts were LDLT. Overall, median recipient's age and weight were 7 months (range, 5 days-22 months) and $5.8 \mathrm{~kg}$ (range, 2.6-8 kg) respectively. Median graft weight was 209 grams (range, 124-264 grams) and median GRWR was 3.5\% (range, 2.7-5.6\%). Hepatic artery and portal vein thrombosis overall incidence were $1.5 \%$ and $4.2 \% ; 120$ out of the 330 pLT were monosegmental (37\%) producing a smaller graft (median of 164 grams) and accordingly a lower GRWR (median 3.2\%) compared to reduced LLS. With a median follow-up of 39 months (range, 6-87 months), the overall graft and patient survival were $84 \%(285 / 340)$ and $89 \%(295 / 330)$.

Discussion: Monosegmental and RLLS/HRLLS grafts provide access to liver transplantation for very small recipients with excellent results comparable to the standard LLS.

Keywords: Monosegmental; monosegment (MSG); reduced; hyper-reduced; left lateral sector graft; liver transplantation

Submitted Sep 02, 2020. Accepted for publication Feb 05, 2021.

doi: $10.21037 / \mathrm{hbsn}-20-792$

View this article at: http://dx.doi.org/10.21037/hbsn-20-792

\section{Introduction}

Liver transplantation is an established method for treating acute and chronic organ failure. Given the obvious difficulties for obtaining suitable grafts in small recipients, the pool of donors was expanded to facilitate access to the waiting list, initially with reduced organs and later on with split grafts (deceased donors) 
as well as living donor liver transplantation (LDLT) (1), being the commonest modality of transplant in children the left lateral sector (LLS) (2).

Nevertheless, the Gordian Knot of the paediatric liver transplantation (pLT) continues to be the large-for-size scenario, seen when the volume of the graft exceeds the capacity of the abdominal cavity (2-6). The alternatives are using a standard LLS and delaying abdominal wall closure $(4,5)$ or surgically altering the LLS and aiming for a primary closure. In 1992, to confront this problem, Strong et al. (6) published the first monosegmental pLT, implanting the segment 3 from a deceased donor (DD) into a 4-month-old baby [a redo transplant for hepatic artery thrombosis (HAT)]. Larger series with DD appeared later, notably from Srinivasan et al. (7). This technique would be further consolidated by Kasahara et al. (8), whom produced reduced left lateral sector (RLLS) grafts and mono-segments from LDLT.

The aim of the present study is to interrogate the literature to evaluate the existing experience and outcomes of monosegment (MSG), RLLS/hyper-reduced left lateral sector (HRLLS) transplants in small paediatric recipients. We present the following article in accordance with the PRISMA reporting checklist (available at https://hbsn. amegroups.com/article/view/10.21037/hbsn-20-792/rc).

\section{Methods}

This systematic review was carried out in accordance with the guidelines set out in the PRISMA checklist (9).

\section{Literature search}

A systematic literature search of articles published from inception until May 2020 performed in Embase, MEDLINE (PubMed), Cochrane library, and Google Scholar databases using free text and MeSH terms (liver pediatric transplantation, monosegments, monosegmental). A grey literature search on www.clinicaltrials.gov was also performed. Bibliographies cited in the retrieved articles were manually checked for further analysis. Disagreements between authors were resolved through discussion.

\section{Search terms, inclusion and exclusion criteria}

Studies reporting paediatric liver transplantation, monosegments or monosegmental grafts, reduced or hyperreduced grafts and left lateral sectors grafts were included in this study. Abstracts (summary of the contents of an article or book) and editorials without original data were excluded.

\section{Data extraction and outcomes}

Two reviewers (PG and $\mathrm{EH}$ ) independently extracted demographic data, operative information and patients' outcomes from the included studies. The data points recorded were: donors' age and weight, donor status (living or cadaveric), recipient indication for liver transplantation, age and recipient weight, donor-to-recipient weight ratio (DRWR), graft-to-recipient weight ratio (GRWR), surgical techniques used for manipulating LLS, segments implanted, postoperative vascular complications, median follow-up, graft and patient overall survival. Row data is presented with mean and media (range) values as well as percentages. Series with $<3$ cases were not considered to avoid "overweight" their values $(6,10,11)$.

\section{Definitions}

The LLS (1) can be modified into: (I) partially reduced grafts, or (II) monosegments. In addition, it can be done before perfusion (in-situ) or afterwards (ex-situ), from DD or LDLT.

RLLS and/or HRLLS refer to those grafts obtained by transecting along peripheral (horizontal and vertical) section planes of the graft. The references tend to be the outflow, not following the Couinaud's segmentation, hence some authors name them "non-anatomical". Those grafts referred as "reduced to segment..." using peripheral planes for transection, were regarded as reduced (12).

Monosegmental liver transplantation refers to any graft including either segment 2 or 3 . This technique is characterised by:

* Following inflow landmarks as per anatomical Couinaud's segmentation.

* There is "disruption" of the Glisson capsule.

* Addresses volume and thickness of the graft.

\section{Query}

Two queries were proposed in this systematic review (SR). First, are the overall results of surgically modifying the LLS comparable to the standard LLS pLT? And second, are the different modalities, MSG and RLLS, comparable?

\section{Statistical analysis}

The methodological quality of each of the included studies 


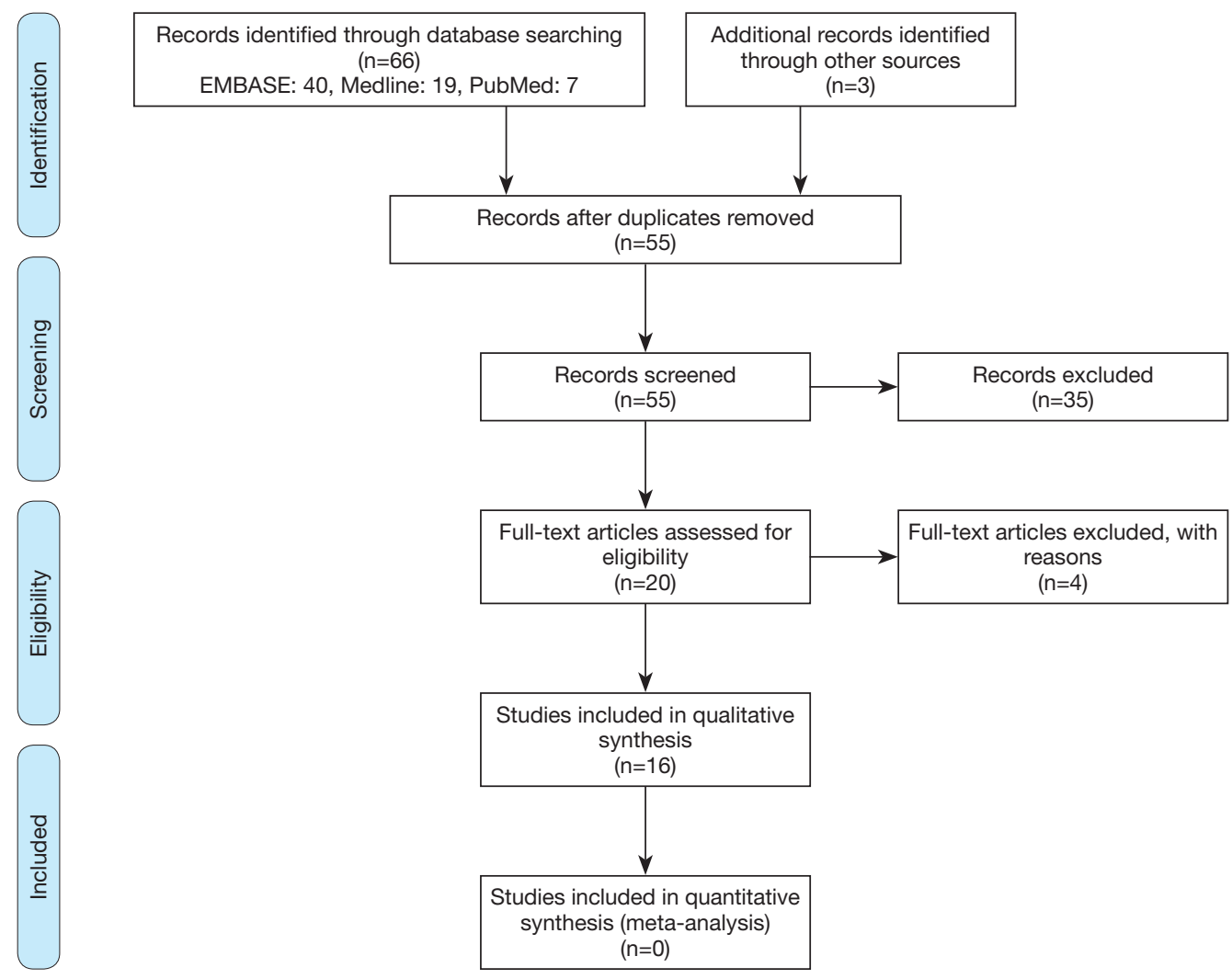

Figure 1 Diagram of the search strategy.

was evaluated for risk of bias using the Risk of Bias in Nonrandomized Studies of Interventions (ROBINS-I) which incorporates seven domains: confounding, selection of participants into the study, classification of interventions, deviations from intended interventions, missing data, measurement of outcomes and selection of reported results. An important feature of ROBINS-I is the use of signalling questions to detect the risk of bias and facilitate assessment within seven bias domains (13). In all analyses, the point estimate was considered significant at $\mathrm{P}<0.05$.

\section{Results}

Sixteen studies from a pool of sixty-two were selected (6,7,10-12,14-24) (Figure 1 and Table 1). Six articles (25-30) were excluded to avoid repetition as more updated publications from the same institutions were identified. This SR includes 330 pLT with a median follow-up of 39 months ranging from 6 to 87 months (composite of each manuscript).

\section{Quality assessment}

The overall quality of the studies included varied from moderate to low. Selection, confounding, underpowered sample, detection, national and institutional bias might have influenced the results (Table S1).

* Overall results (Tables 1,2): there were 37\% MSG and $63 \%$ RLLS/HRLLS grafts. Median recipient age was 7 months (5 days to 22 months) with a median weight of $5.8 \mathrm{~kg}$ (2.6 to $8 \mathrm{~kg})$. Ninety percent of the grafts were LDLT. Mean and median donor/recipient weight ratio was 10 (range, 6.2514). The median implanted graft weight was 209 grams [121-264] generating a median GRWR of $3.5 \%(2.7-5.6 \%)$. HAT and portal vein thrombosis (PVT) overall incidence were $1.5 \%$ and $4.2 \%$. Out of 330 patients, 6 underwent re-transplantation within the first 90 days [2 HAT, 1 primary non function (PNF) and 1 PVT, 2 antimicrobial resistant (AMR)] $(15,21,24)$. With a median followup of 39 (range, 6-87) months, the overall graft and 


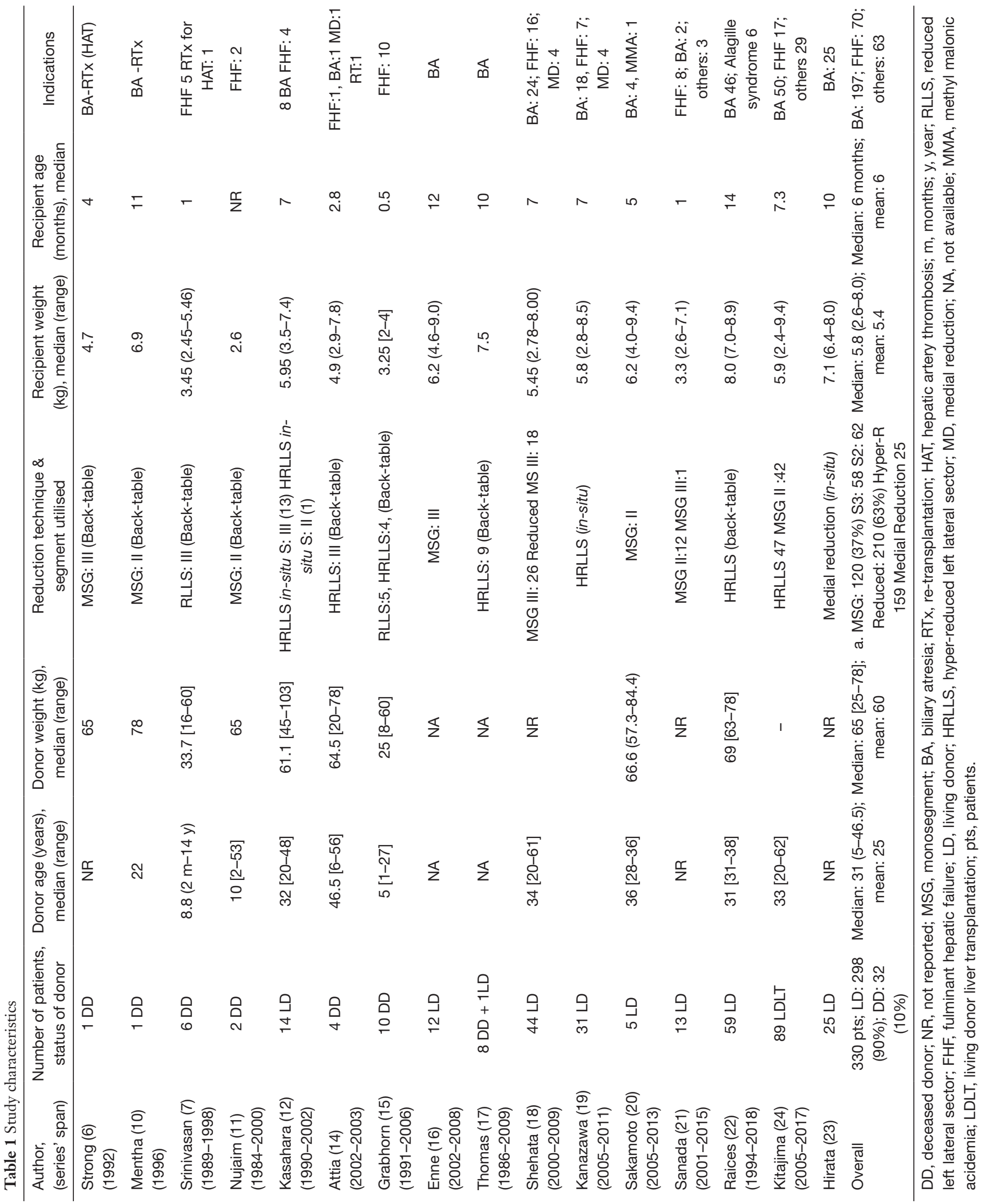


Table 2 Outcome of interests: MSG vs. reduced LLS grafts

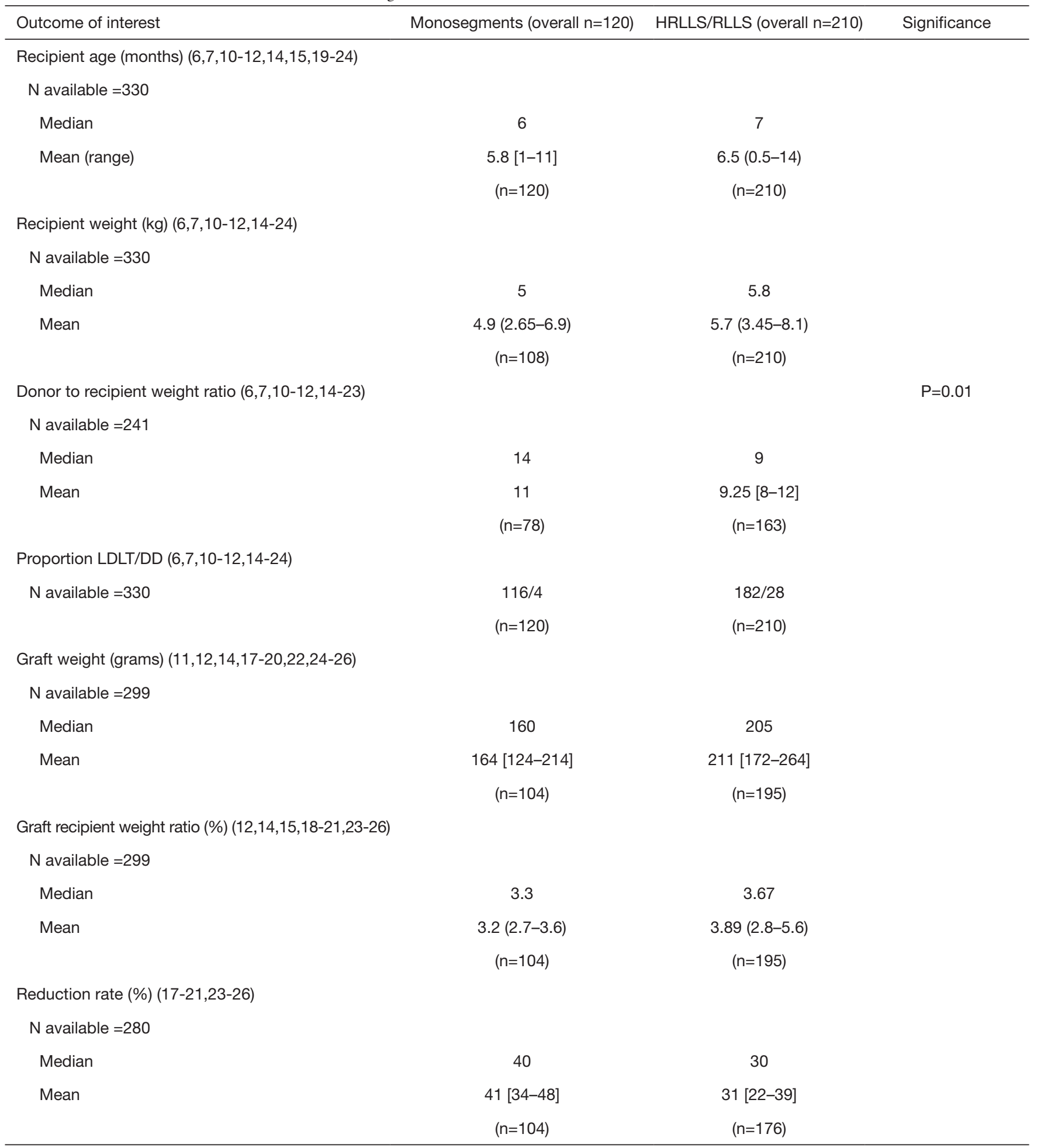

Table 2 (continued) 
Table 2 (continued)

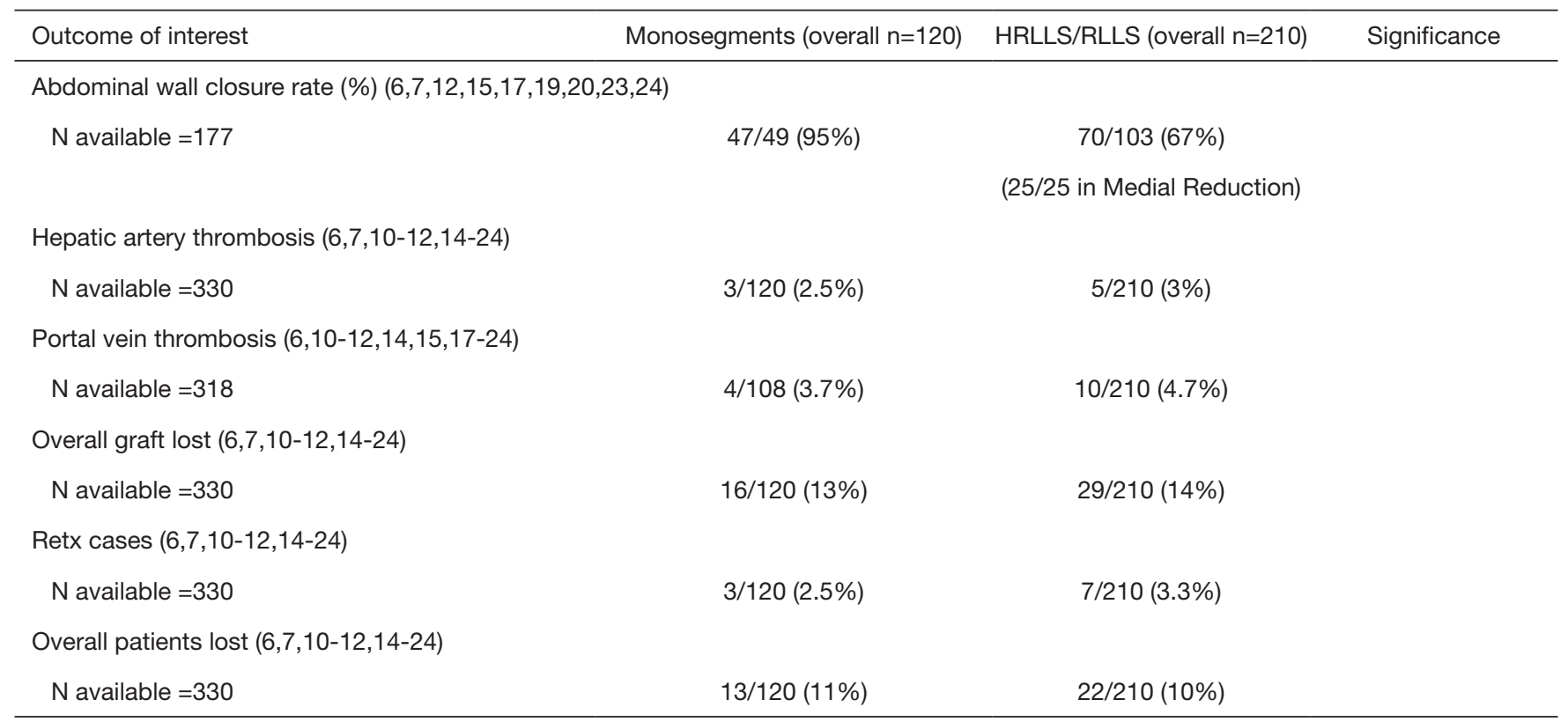

Data are presented with median and mean (including range). Not all the articles provided same amount of data, therefore the size number of each category is shown. MSG, monosegment; LLS, left lateral sector; HRLLS, hyper-reduced left lateral sector; RLLS, reduced left lateral sector; LDLT, living donor liver transplantation; DD, deceased donor.

patient survival were $84 \%$ and $89 \%$ : a total of 35 deaths were reported throughout all publications, some of them due to delayed causes (Table 3).

- Reduced grafts (Table 2): 210/330 were reported as reduced grafts (7), including hyper-reduced $(12,14,15,17-19,22,24)$ and medial (23). Shehata's (18) and Kitajima's (24) series comprise MSG and RLLS. Only three of the ten authors performed the reduction in situ $(19,23,24)$ although it represented $49 \%$ of the series. Actual median graft weight and GRWR obtained were 205 grs [172-264] and 3.67\% (2.8-5.6).

* Monosegmental grafts (Table 2): 120/330 were reported as monosegmental grafts $(6,10,11,16,18,20,21,24)$. The vast majority were LDLT. Recipients were younger and there was a higher DRWR mismatch. Nevertheless, the actual graft weight and GRWR (3.3\%) obtained were smaller than RLLS allowing to go below the 4\% GRWR mark. Vascular complications (HAT and PVT) were no different nor was overall mortality. Only nine publications reported data regarding abdominal wall closure (177 patients). Primary closure was more frequent in MSG $(47 / 49)(6,12,20,24)$ than in RLLS $(70 / 103)(7,15,17,19,24)$, being the medial reduction (25/25) an exception (23).

\section{Discussion}

This is the first systematic review that evaluates the existing evidence with monosegmental and reduced LLS grafts in paediatric liver transplantation over the last 25 years. There is a former manuscript published in 2005 focusing on 7 papers and including $27 \mathrm{MSG}$, arguably labelled as a meta-analysis (29,31-36).

The studies evaluated were quite heterogenous, including single case reports $(6,10)$ and large series. Five of the sixteen studies $(18,19,22-24)$ represented $82 \%$ of the total population (Table 1). In addition, the age ranged from 5 days to 22 months. Some studies included only neonates $(7,15)$ while the rest included infants as well.

The overall median weight of this cohort was $5.8 \mathrm{~kg}$ $(2.6-8 \mathrm{~kg})$ and it clearly represents a complex group of recipients where a significant DRWR mismatch can be expected. This might result not only in a compartment syndrome but can also compromise the inflow and outflow of the graft. Some authors refer to this scenario as a large-for-size syndrome (2-6).

\section{Are the results of surgically manipulating the $L L S$ comparable to the standard LLS?}

This cohort of 330 modified LLS, albeit heterogenous, 
provided an overall graft and patient survival of $84 \%$ and $89 \%$ with a median $\mathrm{FU}$ of 39 months ( 3 years). The incidence of HAT and PVT were $1.5 \%$ and $4.2 \%$. Direct comparison with standard LLS is difficult given historical bias and large series will include a wide range of age and

Table 3 Causes of patients' death

\begin{tabular}{|c|c|c|c|}
\hline Deaths (overall) & ALL & Monosegmental & Reduced LLS \\
\hline - Sepsis & - 15 & - 4 & - 11 \\
\hline - HAT & $\bullet 2$ & $\bullet 1$ & - 1 \\
\hline • PVT & - 1 & - 1 (after retx) & $\bullet-$ \\
\hline - GVHD & - 1 & $\bullet-$ & - 1 \\
\hline $\begin{array}{l}\text { - Pulmonary } \\
\text { haemorrhage }\end{array}$ & $\cdot 1$ & $\bullet-$ & $\bullet 1$ \\
\hline $\begin{array}{l}\text { - Pulmonary } \\
\text { hypertension }\end{array}$ & $\bullet 2$ & - 1 & $\bullet 1$ \\
\hline - Pneumonia & $\bullet 1$ & $\bullet 2$ & $\bullet-$ \\
\hline - CVA & - 4 & - 1 & $\cdot 3$ \\
\hline - MOF & $\bullet 2$ & $\bullet-$ & $\cdot 1$ \\
\hline - Rejection & $\cdot 3$ & $\cdot 3$ & $\bullet-$ \\
\hline \multirow[t]{3}{*}{ - Not specified } & $\cdot 3$ & $\bullet-$ & $\cdot 2$ \\
\hline & & & - 1 \\
\hline & $35 / 330$ & $13 / 120$ & $22 / 210$ \\
\hline RETX (<90 days) & 6 & 1 (PVT) & $\begin{array}{c}3(1 \mathrm{PNF}+2 \\
\text { HAT })\end{array}$ \\
\hline RETX (>90 days) & 4 & $1 \mathrm{PVT}+\mathrm{ACR}$ & $\begin{array}{c}2 \mathrm{ACR}+ \\
\text { sepsis }\end{array}$ \\
\hline
\end{tabular}

LLS, left lateral sector; HAT, hepatic artery thrombosis; PVT, portal vein thrombosis; GVHD, graft vs. host disease; CVA, cerebral vascular accident; MOF, multi-organic failure; PNF, primary non function; RETX, retransplantation; ACR, acute cellular rejection. weights. In fact, the comparison should be made against recipients with similar weight $(5 \mathrm{~kg})$ receiving a standardwhole LLS. A significant consequence in this later approach would be the need for delayed/secondary abdominal wall closure, bridging the gap with a prosthetic or biological mesh $(4,5)$.

Table 4 presents graft and patient overall survival from large series for comparison. Figures reported are not dissimilar to those in MSG and RLLS.

\section{Are the different modalities for surgically manipulating $a$ LLS comparable?}

We found sixteen articles presenting several institutions' strategies to address the issue of a severe GRWR mismatch. Out of 330 pLT, 37\% were MSG and 63\% RLLS.

At birth, the liver represents close to $3.5 \%$ of our Total Body Weight (range, 2.1-4.7), to then gradually become $2-1.5 \%$ (range, $1.8-2.8$ ) in individuals $>17$-year-old (42). An adult LLS might represent $16 \%( \pm 4)$ of the Standard Total Liver Volume (1,518 $\pm 353 \mathrm{cc})$, averaging $242 \pm 79$ cc (31). Accordingly, a $5 \mathrm{~kg}$ child receiving a LLS graft, will likely face a GRWR close to 5\% (1:1 equivalence between cc and grams). It is well documented that GRWR is a strong predictor of graft survival and the vast majority of reports concur that those grafts exceeding $4 \%$ will likely generate a conflict with the abdominal cavity's capacity $(4,5,12,16-20,23,25,43-45)$. Hence, some groups advocate for altering the LLS, reducing or converting it into a monosegment. One should however avoid adopting a very dogmatic view based only on volume, since several other factors (ascites, sarcopenia and specially graft thickness) will have a role in deciding (the myth of 4?) (46). Even though the first MSG was reported by Strong in 1992, there is a clear preference for this technique in Japan, whereas

Table 4 Graft and patient overall survival in paediatric LT

\begin{tabular}{lccccc}
\hline Study & Period & Age & Graft & Patient & Total \\
\hline ELTR (37) & $1988-2015$ & $2-18$ years & $71 \%$ at 3 years & $82 \%$ at 3 years & $\mathrm{n}=5,886$ \\
SRTR (38) & $1897-2018$ & $<18$ years & $75 \%$ at 5 years & $88 \%$ at 5 years & $\mathrm{n}=13,442$ \\
JLTS (39) & $1989-2010$ & NR & NR & $88 \%$ at 1 year & $\mathrm{n}=2,224$ \\
UCLA (40) & $2007-2015$ & $<18$ years & $73 \%$ at 1 year & $86 \%$ at 1 year & $\mathrm{n}=1,000$ \\
SRTR (41) & $2014-2016$ & $<18$ years & $88 \%$ at 3 years & $93 \%$ at 3 years & August 2020 report \\
Current SR & $1995-2019$ & NR & $88 \%$ at 3 years & $90 \%$ at 3 years & $\mathrm{n}=241$
\end{tabular}

ELTR, European Liver Transplant Registry; SRTR, Scientific Registry of Transplant Recipients; JLTS, Japanese Liver Transplant Society; UCLA, University of California LA; SR, systematic review; OS, overall survival; NR, non-reported. 
reduction seems more prevalent in western countries. When both techniques were compared, some differences were encountered (Table 2). Recipients of MSG were younger and lighter with a bigger DRWR mismatch and yet, MSG produced smaller grafts (median of 160 grams), finally achieving a GRWR below $4 \%$. Primary abdominal wall closure was more likely too. The lines of transection for MSG are clearly different from reducing a graft and hence "off-sets" volume and thickness, the only exception being the Medial Reduction described by Hirata et al. (23). Several authors $(20,21,23)$ factor on the direct thickness measurement of the graft (median value $6 \mathrm{~cm}$ in this SR) or the GRDR ( $\mathrm{cm}$ from left hepatic vein to PV bifurcation on preop CT imaging) (21) to select their surgical strategies. Results, in terms of vascular complications and overall survival, were similar (Table 3). In addition, one must take into consideration that MSG were by and large obtained insitu from LDLT (94\%), with all the technical complexity added, in particular shorter and smaller arteries compared with RLLS in DD, where often the celiac axis is left with the LLS.

\section{Limitations}

The results of the present study should be interpreted in the context of its limitations. Assessment of bias within the included studies using ROBINS-I tool demonstrated that the overall quality varied from moderate to low and confounding, selection and detection bias might have affected the results. Furthermore, seven out of sixteen studies included less than 10 patients $(6,7,10,11,14,17,20)$. Five studies (three from Japan, India and Argentina) represented the $67 \%$ of the total sample $(18,19,22,23)$. The time span of the included studies extended over 25 years period. Therefore, institutional, national, underpowered sample, selectional, detection and learning curve bias might have influenced the results.

\section{Conclusions}

The large majority of reports included in this SR would recommend aiming for a GRWR $<4 \%$ to reduce the risks of a large-for-size scenario. RLLS and MSG are both optimal options to facilitate pLT to a very small recipients with results comparable to standard LLS despite the technical complexities. MSG will be able diminish volume and thickness providing the smallest possible graft, in particular Segment 2. Special mention deserves the Medial Reduction which effectively constitutes a non-anatomical reduction of Segment 3 altering volume and thickness and allowing primary closure.

Experience is paramount and needs to be considered in, for these techniques to be seen as an established modality of treatment.

\section{Acknowledgments}

Funding: None.

\section{Footnote}

Reporting Checklist: The authors have completed the PRISMA reporting checklist. Available at https://hbsn. amegroups.com/article/view/10.21037/hbsn-20-792/rc

Conflicts of Interest: Both authors have completed the ICMJE uniform disclosure form (available at https://hbsn. amegroups.com/article/view/10.21037/hbsn-20-792/coif). The authors have no conflicts of interest to declare.

Ethical Statement: The authors are accountable for all aspects of the work in ensuring that questions related to the accuracy or integrity of any part of the work are appropriately investigated and resolved.

Open Access Statement: This is an Open Access article distributed in accordance with the Creative Commons Attribution-NonCommercial-NoDerivs 4.0 International License (CC BY-NC-ND 4.0), which permits the noncommercial replication and distribution of the article with the strict proviso that no changes or edits are made and the original work is properly cited (including links to both the formal publication through the relevant DOI and the license). See: https://creativecommons.org/licenses/by-nc-nd/4.0/.

\section{References}

1. Pang YY. The Brisbane 2000 terminology of liver anatomy and resections. HPB 2000;2:333-39. HPB (Oxford) 2002;4:99; author reply 99-100.

2. Broelsch CE, Emond JC, Whitington PF, et al. Application of reduced-size liver transplants as split grafts, auxiliary orthotopic grafts, and living related segmental transplants. Ann Surg 1990;212:368-75; discussion 375-67.

3. Ogawa K, Kasahara M, Sakamoto S, et al. Living donor liver transplantation with reduced monosegments 
for neonates and small infants. Transplantation 2007;83:1337-40.

4. Goldaracena N, Echeverri J, Kehar M, et al. Pediatric living donor liver transplantation with large-for-size left lateral segment grafts. Am J Transplant 2020;20:504-12.

5. Gül-Klein S, Dziodzio T, Martin F, et al. Outcome after pediatric liver transplantation for staged abdominal wall closure with use of biological mesh-Study with long-term follow-up. Pediatr Transplant 2020;24:e13683.

6. Strong R, Lynch S, Yamanaka J, et al. Monosegmental liver transplantation. Surgery 1995:118:904-6.

7. Srinivasan P, Vilca-Melendez H, Muiesan P, et al. Liver transplantation with monosegments. Surgery 1999;126:10-2.

8. Kasahara M, Kaihara S, Oike F, et al. Living-donor liver transplantation with monosegments. Transplantation 2003;76:694-6.

9. Moher D, Liberati A, Tetzlaff J, et al. Preferred reporting items for systematic reviews and meta-analyses: the PRISMA statement. PLoS Med 2009;6:e1000097.

10. Mentha G, Belli D, Berner M, et al. Monosegmental liver transplantation from adult to an infant. Transplantation 1996;62:1176-78.

11. Noujaim HM, Mayer DA, Buckles JA, et al. Techniques for and outcome of liver transplantation in neonates and infants weighing up to 5 kilograms. J Pediatr Surg 2002;37:159-64.

12. Kasahara M, Uryuhara K, Kaihara S, et al. Monosegmental living donor liver transplantation. Transplant Proc 2003;35:1425-6.

13. Sterne JAC, Hernan MA, Reeves BC, et al. ROBINS-I: a tool for assessing risk of bias in non-randomised studies of interventions. BMJ 2016;355:i4919.

14. Attia MS, Stringer MD, McClean P, et al. The reduced left lateral segment in pediatric liver transplantation: An alternative to the monosegment graft. Pediatr Transplant 2008;12:696-700.

15. Grabhorn E, Richter A, Fischer L, et al. Emergency liver transplantation with acute failure: Long-term follow-up. Transplantation 2008;86:932-6.

16. Enne M, Pacheco-Moreira L, Balbi E, et al. Hepatic artery reconstruction in pediatric living donor liver transplantation under $10 \mathrm{Kg}$, without microscope use. Pediatr Transplant 2010;14:48-51.

17. Thomas N, Thomas G, Verran D, et al. Liver transplantation in children with hyper-reduced grafts-A single-center experience. Pediatr Transplant 2010;14:426-30.
18. Shehata MR, Yagi S, Okamura Y, et al. Pediatric Liver Transplantation using reduced and hyper-reduced left lateral segment grafts: A 10-year single-center experience. Am J Transplant 2012;12:3406-13.

19. Kanazawa H, Sakamoto S, Fukuda A, et al. Livingdonor liver transplantation with hyperreduced left lateral segment grafts: a single-center experience. Transplantation 2013;95:750-4.

20. Sakamoto S, Kanazawa H, Shigeta T, et al. Technical considerations of living donor hepatectomy of segment 2 grafts for infants. Surgery 2014;156:1232-7.

21. Sanada Y, Hishikawa S, Okada N, et al. Dorsal approach plus branch patch technique is the preferred method for liver transplanting small babies with monosegmental grafts. Langenbecks Arch Surg 2017;402:123-33.

22. Raices M, Czerwonko ME, Ardiles V, et al. Short- and Long-term outcomes after live-donor transplantation with hyper-reduced liver grafts in low-weight pediatric recipients. J Gastrointest Surg 2019;23:2411-20.

23. Hirata Y, Agarawal S, Varma S, et al. The impact of medial reduction of left lateral segment, a novel technique for living donor liver transplantation for small pediatric recipients. Liver Transpl 2020;26:1534-8.

24. Kitajima T, Sakamoto S, Sasaki K, et al. Impact of graft thickness reduction of left lateral segment on outcomes following pediatric living donor liver transplantation. Am J Transplant 2018;18:2208-19.

25. Yamada N, Sanada Y, Hirata Y, et al. Selection of Living donor liver grafts for patients weighing $6 \mathrm{Kg}$ or less. Liver Transpl 2015:21:233-8.

26. Sakuma Y, Sasanuma H, Miki A, et al. Living-Donor liver transplantation using segment 2 monosegment graft: A single-center experience. Transplant Proc 2016;48:1110-4.

27. de Santibañes E, McCormack L, Mattera J, et al. Partial left lateral segment transplant from a living donor. Liver Transpl 2000;6:108-12.

28. Enne M, Pacheco-Moreira LF, Cerqueira A, et al. Liver transplantation with monosegment from a living donor. Pediatr Transplant 2004;8:189-91.

29. Enne M, Pacheco-Moreira LF, Balbi E, et al. Liver transplantation with monosegments. Technical aspects and outcome: A meta-analysis. Liver Transpl 2005;11:564-9.

30. Kasahara M, Sakamoto S, Sasaki K, et al. Living donor liver transplantation during the first 3 months of life. Liver Transpl 2017;23:1051-7.

31. Abdalla EK, Denys A, Chevalier P, et al. Total and segmental liver volume variations: Implications for liver surgery. Surgery 2004;135:404-10. 
32. Muller X, Marcon F, Sapisochin G, et al. Defining benchmarks in liver transplantation: A multicentre outcome analysis determining best achievable results. Ann Surg 2018;267:419-25.

33. Glinka J, de Santibañes M, Biagiola D, et al. Biliary reconstruction before clamp removal to avoid portal vein thrombosis in pediatric living-donor liver transplantation using hyper-reduced left lateral segment grafts: a novel technical strategy. Pediatr Transplant 2019;23:e13516.

34. Bekker J, Ploem S, de Jong KP. Early hepatic artery thrombosis after liver transplantation: a systematic review of the incidence, outcome and risk factors. Am J Transplant 2009;9:746-57.

35. Shirouzu Y, Kasahara M, Morioka D, et al. Vascular reconstruction and complications in living donor liver transplantation in infants weighing less than 6 Kilograms: the Kyoto experience. Liver Transpl 2006;12:1224-32.

36. Reichert PR, Renz JF, D'Albuquerque LA, et al. Surgical anatomy of the left lateral segment as applied to livingdonor and split-liver transplantation: a clinicopathological study. Ann Surg 2000;232:658-64.

37. European Liver Transplant Registry, 1988-2015 report. Available online: http://www.eltr.org/Pediatrictransplantation.html

38. Bowring MG, Massie AB, Chu NM, et al. Projected 20and 30-Year Outcomes for Pediatric Liver Transplant Recipients in the United States. J Pediatr Gastroenterol

Cite this article as: Gavriilidis P, Hidalgo E. Alternatives to left lateral sector in paediatric liver transplantation-a systematic review on monosegmental and reduced grafts. HepatoBiliary Surg Nutr 2022;11(4):567-576. doi: 10.21037/hbsn-20-792
Nutr 2020;70:356-63.

39. Kasahara M, Sakamoto S, Umeshita K. Uemoto Effect of graft mismatching on pediatric living-donor liver transplantation in Japan. Exp Clin Transplant 2014;12:1-4.

40. Venick RS, Farmer DG, Soto JR, et al. One Thousand Pediatric Liver Transplants During Thirty Years: Lessons Learned. J Am Coll Surg 2018;226:355-66.

41. Scientific Registry of Transplant Recipients, August 2020 report. Available online: https://www.srtr.org/reportstools/posttransplant-outcomes/

42. Johnson TN, Tucker GT, Tanner MS, et al. Changes in liver volume from birth to adulthood: A Meta-Analysis. Liver Transpl 2005;11:1481-93.

43. Kasahara M, Umeshita K, Inomata $Y$, et al. Long-term outcomes of pediatric living donor liver transplantation in Japan: an analysis of more than 2200 cases listed in the registry of the Japanese Liver Transplantation Society. Am J Transplant 2013;13:1830-9.

44. Kiuchi T, Kasahara M, Uryuhara K, et al. Impact of graft size mismatching on graft prognosis in liver transplantation from living donors. Transplantation 1999;67:321-7.

45. Li JJ, Zu CH, Li SP, et al. Effect of graft size matching on pediatric living-donor liver transplantation at a single center. Clin Transplant 2018;32.

46. Rammohan A, Gunasekaran V, Reddy MS, et al. Graft reduction in pediatric liver transplantation: The myth of 4 ? Am J Transplant 2018;18:3081-2. 


\section{Supplementary}

Table S1 Risk of bias of the included studies

\begin{tabular}{|c|c|c|c|c|c|c|c|}
\hline Author, country, year & $\begin{array}{l}\text { Confounding } \\
\text { bias }\end{array}$ & Selection & classification & $\begin{array}{l}\text { Deviation from intended } \\
\text { interventions }\end{array}$ & $\begin{array}{l}\text { Missing } \\
\text { data }\end{array}$ & $\begin{array}{c}\text { Measurement of } \\
\text { outcomes }\end{array}$ & $\begin{array}{l}\text { Selective } \\
\text { reporting }\end{array}$ \\
\hline Strong, Australia, 1995 & High & High & Moderate & Low & Low & Low & Low \\
\hline Srinivasan, 1999, UK & Moderate & High & Moderate & Low & Low & Low & Low \\
\hline Kasahara, 2003, Japan & Moderate & Moderate & Moderate & Low & Low & Low & Low \\
\hline Attia, 2008, UK & High & Moderate & Moderate & Low & Low & Low & Low \\
\hline $\begin{array}{l}\text { Grabhorn, 2008, } \\
\text { Germany }\end{array}$ & Moderate & Moderate & Moderate & Low & Low & Low & Low \\
\hline Shehata 2012, Japan & Moderate & Moderate & Moderate & Moderate & Low & Low & Low \\
\hline $\begin{array}{l}\text { Kanazawa, 2013, } \\
\text { Japan }\end{array}$ & Moderate & Moderate & Moderate & Low & Low & Low & Low \\
\hline $\begin{array}{l}\text { Sakamoto, 2014, } \\
\text { Japan }\end{array}$ & High & Moderate & Moderate & Low & Low & Low & Low \\
\hline Yamada, 2015, Japan & Moderate & Moderate & Moderate & Low & Low & Low & Low \\
\hline Sakuma, 2016, Japan & Moderate & Moderate & Moderate & Low & Low & Low & Low \\
\hline Sanada, 2017, Japan & Moderate & Moderate & Moderate & Low & Low & Low & Low \\
\hline
\end{tabular}

